\title{
PENGARUH EFEKTIVITAS PRAKTIK KERJA INDUSTRI TERHADAP KESIAPAN KERJA SISWA KELAS XI PROGRAM KEAHLIAN TEKNIK BANGUNAN SMK NEGERI 1 CIBINONG - KABUPATEN BOGOR
}

\author{
Mochmad Fauri ${ }^{1}$, Amos Neolaka ${ }^{2}$, Riyan Arthur ${ }^{3}$ \\ ${ }^{1}$ Alumni PTB FT UNJ, fauzi m@gmail.com \\ ${ }^{2}$ Dosen PTB FT UNJ, aneolaka@unj.ac.id \\ ${ }^{3}$ Dosen PTB FT UNJ, arthur@unj.ac.id
}

\begin{abstract}
Abstrak
Tujuan penelitian ini adalah mengetahui tingkat kesiapan kerja berdasarkan efektivitas praktik kerja industri terhadap siswa SMK Negeri 1 Cibinong Kelas XI Program Keahlian Teknik Bangunan. Praktik kerja industri merupakan salah satu pengaruh positif yang memberikan sikap kesiapan kerja pada siswa SMK Negeri 1 Cibinong.

Penelitian ini menggunakan metode survei dengan melakukan pendekatan korelasional. Metode ini digunakan untuk memperoleh infomrasi hubungan antar variabel yang akan diteliti.

Hasil penelitian menunjukan bahwa efektivitas praktik kerja industri berpengaruh positif dan signifikan terhadap kesiapan kerja siswa SMK Negeri 1 Cibinong Kabupaten Bogor. Efektivitas praktik kerja industri memberikan determinasi sebesar 50,81\% terhadap kesiapan kerja dengan persamaan regresi $\mathrm{Y}=43,482+0,393 \mathrm{X}$ yaitu pengaruh efektivitas praktik kerja industri terhadap variabel kesiapan kerja adalah positif. Semakin tinggi efektivitas praktik kerja industri, maka semakin tinggi pula kesiapan untuk bekerja.
\end{abstract}

Kata kunci: Prakerin, Efektivitas, Kesiapan Kerja

\section{THE EFFECTIVENESS INFLUENCE OF PRACTICAL INDUSTRY TRAINING TO WORKING READLINES OF GRADE XI BUILDING ENGINEERING OF 1 SENIOR HIGH SCHOOL CIBINONG STUDENTS BOGOR CITY}

\author{
Mochmad Fauri ${ }^{1}$, Amos Neolaka², Riyan Arthur \\ ${ }^{1}$ Alumni of PTB FT UNJ, fauri m@gmail.com \\ ${ }^{2}$ Lecturer of PTB FT UNJ, aneolaka@, unj.ac.id \\ ${ }^{3}$ Lecturer of PTB FT UNJ, arthur@,unj.ac.id
}

\begin{abstract}
The purpose of this study is to know the level of readiness work based on the effectiveness of industrial work practices to students SMK Negeri 1 Cibinong Class XI Building Engineering Programs. Industrial work practice is one of the positive influences that provide attitude readiness work on students SMK Negeri 1 Cibinong.

This research used survey method with correlational approach. This method is used to obtain information relation between variables to be studied.
\end{abstract}


The results showed that the effectiveness of industrial work practices have a positive and significant effect on the readiness of the students of SMK Negeri 1 Cibinong Bogor Regency. The effectiveness of industrial work practice gives determination equal to 50,81\% to readiness of work with regression equation $Y=43,482+$ $0,393 X$ that influence effectivity of industrial work practice to work preparedness variable is positive. The higher the effectiveness of industrial work practices, the higher the readiness to work.

Keywords: Prakerin, Effectiveness, Readiness Work

\section{Pendahuluan}

Sekolah Menengah Kejuruan (SMK) menjadi salah satu jalan keluar dalam menyiapkan sumber daya manusia yang potensial. Tujuan ini kemudian dijelaskan pada Undang-Undang Nomor 20 Tahun 2003 tentang Sistem Pendidikan Nasional (UUSPN). Pasal 15 menyebutkan bahwa "Pendidikan kejuruan merupakan pendidikan menengah yang mempersiapkan peserta didik terutama untuk bekerja dalam bidang tertentu" (Kemendikbud, 2003). Secara konstitusi, menunjukan bahwa penyelenggaraan SMK mempunyai peranan yang strategis dalam menentukan pembangunan nasional. Hal itu sejalan dengan kebutuhan sumber daya manusia yang memiliki kompetensi sesuai bidang keahlian yang dibutuhkan oleh dunia usaha/dunia industri (DU/DI).

Struktur kurikulum SMK dibagi menjadi komponen normatif, adaptif dan produktif yang dapat ditempuh selama 3 atau 4 tahun. Komponen normatif bertujuan agar peserta didik menjadi masyarakat yang berperilaku sesuai dengan nilai-nilai dalam kehidupan masyarakat. Komponen adaptif bertujuan untuk membuat peserta didik mampu beradaptasi dan mengembangkan diri susuai kehidupan bermasyarakat dan bernegara. Sementara komponen produktif bertujuan agar peserta didik mampu melaksanakan tugas didunia kerja sesuai dengan program keahlian. Wina Sanjaya menjelaskan kompetensi dalam komponen produktif merupakan standar kompetensi yang berlaku di bidang keahlian yang ditetapkan asosiasi profesi, hasil inventarisasi dan konsensus dunia kerja, serta pihak terkait (Sanjaya, 2008).

Menurut Wena (1965), tujuan dilaksanakannya pendidikan kejuruan didefinisikan: Pendidikan kejuruan bertujuan mempersiapkan peserta didik untuk mampu memasuki lapangan kerja, dapat mengembangkan diri dalam pekerjaan dan dapat menjadi tenaga kerja yang profesional. dengan demikian para peserta didik diharapkan mampu mengembangkan pengetahuan-pengetahuan dasar yang telah dipelajarinya di bangku sekolah, sehingga dapat menjadi pekerja yang produktif dan dapat beradaptasi dengan segera terhadap perubahan yang terjadi.

Berpijak pada uraian konsepsi pendidikan kejuruan seperti yang dijelaskan Wena, secara jelas nampak kaitan yang amat erat antara lembaga pendidikan kejuruan, dengan dunia kerja. Hal ini berarti dalam proses pendidikan kejuruan membutuhkan dua tempat yang berbeda untuk menunjang kesiapan kerja peserta didik. Dua tempat tersebut adalah sekolah dan dunia industri. Hal ini sejalan dengan pendapat Battacharya dan Mandke yang dikutip Wena, bagi (Wena, 1996) "lembaga pendidikan teknologi kejuruan tanpa memanfaatkan dunia industri sebagai tempat belajar akan sulit menghasilkan lulusan yang dapat memahami dunia kerja"

Praktik Kerja Industri (Prakerin) merupakan wujud nyata dari penyelenggaraan pendidikan keahlian 
profesional, yang memadukan secara sistematik antara pendidikan di sekolah dan program penguasaan keahlian yang diperoleh dari bekerja secara langsung di dunia industri, seperti yang dikatakan oleh Soewarni (Wena, 1996).

Prakerin dilaksanakan dengan menerjunkan langsung siswa pada dunia industri yang berkaitan dengan bidangnya masing-masing. Kegiatan bekerja sambil belajar yang dilaksanakan saat prakerin dapat menambah wawasan siswa terhadap dunia kerja. Dengan demikian siswa dapat memperoleh pengalaman baru yang diharapkan akan menjadi bekal setelah menempuh pendidikan di SMK, karena telah menguasai suatu keterampilan kerja tertentu. Dengan dikuasainya keterampilan kerja tertentu siswa memiliki kesiapan untuk bekerja di dunia industri.

Menurut Hamalik, "Praktik Industri atau dibeberapa sekolah disebut dengan $O n$ The Job Training (OJT) merupakan model pelatihan yang diselenggarakan di lapangan, bertujuan untuk memberikan kecakapan yang diperlukan dalam pekerjaan tertentu sesuai dengan tuntutan kemampuan bagi pekerjaan" (Hamalik, 2007) berdasarkan pendapat tersebut, diketahui bahwa prakerin dianggap menjadi salah satu aspek penting dalam membentuk pengetahuan dan keterampilan siswa. Karena dengan prakerin seorang siswa terjun langsung dan menjadi memiliki pengalaman tentang situasi bekerja yang sesungguhnya, sehingga siswa memiliki kesiapan kerja yang tinggi setelah lulus.

Kesiapan kerja dapat diartikan sebagai suatu kondisi yang menunjukan adanya keserasian antara kematangan fisik, mental, serta pengalaman sehingga individu mempunyai kemampuan untuk melaksanakan kegiatan tertentu dalam hubungannya dengan pekerjaan atau kegiatan (Yanto, 2006). Kesiapan kerja menjadi faktor penting yang diperhatikan oleh lembaga pendidikan kejuruan, dalam hal ini SMK.

Dalyono (2005), mengungkapkan "kesiapan adalah kemampuan yang cukup baik fisik dan mental. Kesiapan fisik berarti tenaga yang cukup dan kesehatan yang baik, sementara kesiapan mental memiliki minat dan motivasi yang cukup untuk melakukan suatu kegiatan.

Penduduk dan Tenaga Kerja (2011) memaparkan "Pada Tahun 2010 penduduk di Kabupaten/Kota Jawa Barat yang terbanyak di Kabupaten/Kota Jawa Barat yang terbanyak di Kabupaten Bogor, yaitu sebesar 4,8 juta jiwa. Jumlah Rumah tangga tertinggi berada di Kabupaten Bogor, yaitu 1.037.408 rumah tangga. Jumlah penduduk Miskin di Jawa Barat sebesar 4.852.520 ribu jiwa dan penduduk miskin tertinggi berada di Kabupaten Bogor yaitu 446,04 ribu jiwa atau 9,19 persen. Pengangguran di Jawa Barat sebesar 2079830 orang sebesar 10,96 persen. Bila dilihat berdasarkan tingkat pendidikan, jumlah pencari kerja pada tahun 2010 kelompok yang paling banyak berasal dari jenjang SLTA sebesar 51,65 persen.”

Berdasarkan dari data tersebut diatas untuk lembaga pendidikan kejuruan di Kabupaten Bogor untuk program keahlian teknik bangunan hanya berada di satu sekolah yaitu di SMK Negeri 1 Cibinong. SMKN 1 Cibinong merupakan sekolah menengah kejuruan yang membuka pendidikan kejuruan sesuai dengan minat setelah menamatkan pendidikan Sekolah Menengah Pertama. SMKN 1 Cibinong memiliki misi menyelenggarakan pembelajaran kejuruan yang berbudaya lingkungan, inovatif, kreatif, dan kompetitif serta mampu menegembengkan diri secara. Dapat diambil kesimpulan bahwa SMKN 1 Cibinong berusaha untuk melahirkan sumber daya manusia yang memiliki kesiapan kerja dan sikap profesional guna memenuhi permintaan dunia industri. Dalam hal ini memiliki lulusan dengan kesiapan kerja tinggi merupakan hal yang sangat dijaga dan dijamin oleh sekolah.

Praktek Kerja Industri (Prakerin) sebagai salah satu bentuk penyelenggaraan dari pendidikan sistem ganda di pendidikan kejuruan, juga dilaksanakan oleh SMKN 1 Cibinong. Setiap semester genap maupun ganjil, pihak sekolah bekerja sama dengan 
pihak perusahaan menyalurkan siswa untuk menyelesaikan salah satu kewajibannya, yaitu prakerin. Setelah kembali ke sekolah siswa SMKN 1 Cibinong diharapkan memiliki pengalaman kerja dan memiliki kompetensi tertentu, yang berimbas pada kesiapan kerja siswa yang tinggi.

Berdasarkan studi pendahuluan yang dilakukan oleh peneliti, di program keahlian teknik bangunan SMKN 1 Cibinong, melalui proses observasi dan wawancara menunjukan bahwa kesiapan kerja siswa program keahlian teknik bangunan belum sesuai dengan apa yang menjadi cita-cita pihak sekolah. Siswa merasa belum memiliki ambisi untuk maju dan berusaha untuk mengikuti perkembangan bidang keahlian. Kendati sebelumnya, siswa telah melaksanakan program prakerin selama 3 bulan di industri. Siswa tetap merasa kurang dengan apa yang telah dikerjakan ketika prakerin.

Hal ini dimungkinkan, karena beberapa siswa mengutarakan bahwa pekerjaan yang dilakukan di industri belum cukup sesuai dengan apa yang mereka pelajari di sekolah. Penugasan yang diberikan oleh instrukturnya di industri kadangkala tidak sesuai dengan standar kompetensi lulusan teknik bangunan SMKN 1 Cibinong dan masih banyak lagi masalah yang menjadikan program praktik kerja industri menjadi belum efektif. Namun siswa tidak bisa berbuat banyak karena tidak ada pilihan lain, mengerjakan pekerjaan yang diberikan oleh instrukturnya atau tidak melakukan pekerjaan sama sekali.

Berdasarkan uraian latar belakang permasalahan tersebut, penelitian ini perlu melakukan penelitian Pengaruh Efektivitas Praktik Kerja Industri Terhadap Kesiapan Kerja Siswa Kelas XII Program Keahlian Teknik Bangunan SMK Negeri 1 Cibinong.

\section{Metode Penelitian}

Metode yang digunakan dalam penelitian ini adalah metode survei dengan pendekatan korelasional. Metode survei ini dipilih untuk memperoleh informasi hubungan antar variabel yang diteliti, karena salah satu tujuan dari metode survei adalah menentukan hubungan sesuatu yang hidup di antara kejadian spesifik.

\section{Hasil dan Pembahasan}

Makna dari hasil analisis adalah efektivitas praktik kerja industri memiliki pengaruh yang positif dan signifikan terhadap kesiapan kerja. Semakin tinggi efektivitas praktik kerja industri, maka akan semakin tinggi pula kesiapan kerjanya.

Kesiapan kerja merupakan kunci seseorang yang akan bekerja memiliki nilai tambah. Tanpa kesiapan kerja mustahil seseorang akan mampu untuk bisa melaksanakan beban tugas dan tanggung jawab pekerjaannya. Kesiapan kerja tergantung pada tahap kematangan pengalaman serta kondisi mental dan emosi yang meliputi kemauan untuk bekerja sama dengan orang lain, bersikap kritis, kesediaan menerima tanggung jawab, serta ambisi untuk mau dan kemampuan menyesuaikan diri dengan lingkungan kerja.

Tabel 1. Hasil Pengujian

\begin{tabular}{ll|lc|l}
\hline No & \multicolumn{2}{c}{ Analisis } & Nilai & \multirow{2}{*}{ Kesimp. } \\
\hline 1 & Persamaan Regresi & Y=43,482+0,393X & \\
\hline 2 & Uji & $F_{\text {hitung }}$ & 52,477 & Regresi \\
\cline { 3 - 4 } & Linearitas & $F_{\text {tabel }}$ & 3,93 & Linear \\
\hline \multirow{2}{*}{3} & Signifikansi & $F_{\text {hitung }}$ & 6,819 & Regresi \\
\cline { 3 - 4 } & Regresi & $F_{\text {tabel }}$ & 3,93 & Signifikan \\
\hline \multirow{2}{*}{4} & Korelasi & & 0,581 & Kuat \\
\hline 5 & Signifikansi & thitung & 7,244 & Korelasi \\
\cline { 3 - 4 } & Korelasi & $t_{\text {tabel }}$ & 1,659 & Signifikan \\
\hline
\end{tabular}

Dengan efektifnya pelaksanaan program praktik kerja industri, maka siswa SMK akan memiliki pengalaman kerja dan gambaran tentang kondisi dunia kerja yang sesungguhnya. Pengalaman yang diperoleh siswa selama melaksanakan prakerin ini diharapkan juga mampu melahirkan wawasan, keterampilan, pola pikir, sikap dan tingkah laku dalam bekerja di bidang keahliannya masing-masing. Sehingga terdapat pengaruh positif dan signifikan antara efektivitas praktik kerja industri terhadap kesiapan kerja.

Hasil penelitian ini adalah Efektivitas praktik kerja industri berkotribusi positif 
dan signifikan terhadap kesiapan kerja siswa SMK Negeri 1 Cibinong - Kabupaten Bogor. Efektivitas praktik kerja industri memberikan determinasi $50,81 \%$ terhadap kesiapan kerja dengan persamaan regresi $\mathrm{Y}=43,482+0,393 \mathrm{X}$ yaitu pengaruh Efektivitas Praktik Kerja Industri terhadap variabel Kesiapan kerja adalah positif. Menunjukan bahwa kenaikan dari Efektivitas praktik kerja industri akan diikuti oleh kenaikan Kesiapan kerja. Jika dimisalkan Efektivitas praktik kerja industri naik sebesar 10 unit satuan, maka Kesiapan kerja menjadi 3,39 unit satuan (diperoleh dari : $0,393 \times 10$ ) yaitu bila diketahui $X=50$, maka nilai $\mathrm{Y}$ dihitung perkiraannya sebagai berikut $Y=43,482+0,393(50)=63,132$.

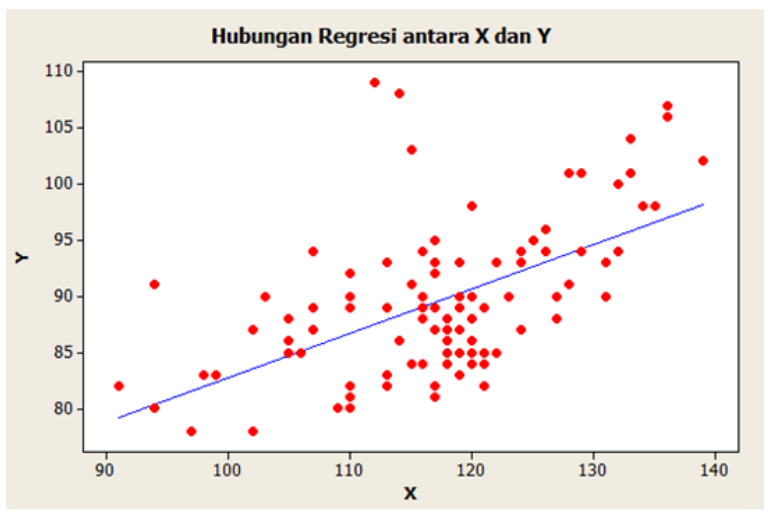

Gambar 1. Grafik Hubungan Regresi Antara Efektivitas Praktik Kerja Industri (X) dan Kesiapan Kerja (Y)

\section{Kesimpulan}

Berdasarkan hasil dan pembahasan yang telah peneliti uraikan pada bab IV, maka dapat di ambil kesimpulan umum bahwa tingkat Kesiapan Kerja Siswa Kelas XI Program Keahlian Teknik Bangunan SMK Negeri 1 Cibinong - Kabupaten Bogor terdorong dalam katagori siap untuk bekerja, maka dapat ditarik kesimpulan bahwa ada pengaruh yang positif dan signifikan antara efektivitas praktik kerja industri terhadap kesiapan kerja pada siswa program keahlian teknik bangunan SMK Negeri 1 Cibinong.

\section{Implikasi}

Efektivitas Praktik Kerja Industri merupakan suatu proses yang dilaksanakan oleh siswa untuk mencapai tujuan tertentu dalam suatu perusahaan dan mambu memberiakan keyakinan yang memadai bagi pihak tempat praktik kerja industri dan pihak sekolah. Hasil penelitian ini menunjukkan bahwa Efektivitas Praktik Kerja Industri berpengaruh terhadap Kesiapan Kerja Siswa. Hal ini mengandung implikasi agar kedepannya pihak perusahaan dan sekolah lebih memperhatikan dan memperbaiki pengawasan dan manajemen Praktik Kerja Industri agar dapat meningkatkan Kesiapan Kerja Siswa sehingga tujuan Sekolah tercapai

\section{Saran}

Rekomendasi yang diberikan dari hasil penelitian ini sebagai berikut:

1. Bagi Peneliti hendaknya memperhatikan variabel lain yang dapat mempengaruhi kesiapan kerja siswa.

2. Bagi guru dan pihak sekolah, perbaiki buku pedoman prakerin agar lebih efektif, sangat penting untuk mengarahkan siswanya untuk lebih meningkatkan keterampilan kerjanya yang berkaitan dengan kesiapan kerja dan hendaknya lebih baik lagi dalam pelaksanaan praktik kerja industri sehingga memperoleh pengalaman kerja yang akan bermanfaat ketika peserta diklat memasuki dunia kerja.

3. Bagi siswa, dalam meningkatkan kesiapan kerja, sebaiknya siswa lebih meningkatkan keterampilan kerja dalam melaksanakan praktik kerja industri, karena persainggan dunia kerja yang semakin ketat.

4. Bagi tempat parktik kerja industri, lebih bisa membimbing serta mengawasi siswa yang sedang praktik agar lebih bisa terkontrol kerjanya di lapangan. 


\section{Daftar Pustaka}

Dalyono. (2005). Psikologi Pendidikan. Jakarta: Rineka Cipta.

Hamalik, Oemar. (2007). Manajemen Pelatihan Ketenagakerjaan. Jakarta: Bumi Aksara.

Sanjaya, Wina. (2008). Pembelajaran Dalam Implementasi Kurikulum Berbasis Kompetensi. Jakarta: Kencana.

Wena, Made. (1996). Pendidikan Sistem Ganda. Bandung: Tarsito.

Yanto, Agus Fitri. (2006). Ketidaksiapan Memasuki Dunia Kerja Karena Pendidikan. Jakarta: Dinamika Cipta. 